\title{
Acute Spinal Cord Injury in the Rat: Comparison of Three Experimental Techniques
}

\author{
Moe Khan and Robert Griebel
}

\begin{abstract}
SUMMARY: Three techniques to produce experimental spinal cord injuries in the rat are compared; 1) the weight dropping method, 2) the aneurysm clip compression method and 3) the extradural balloon compression method. In principle, different forces were used in technique one, while a constant force for different durations is maintained in techniques two and three. The relationship between these different types of injuries and subsequent clinical recovery was assessed quantitatively by the inclined plane method of Rivlin and Tator. The weight dropping technique was found unreliable for experimental spinal cord injury in the rat while the aneurysm clip compression technique resulted in consistent cord injuries with respect to subsequent clinical recovery. The extradural balloon compression method invariably resulted in complete recovery after three and five minutes but no recovery after seven minutes of 0.1 $\mathrm{cc}$ air inflated balloon compression of the cord indicating a steep dose - response curve. However, using a $0.2 \mathrm{cc}$ air inflated balloon, no recovery was noted after one minute compression. The major factor in the pathogenesis of spinal cord injury produced by the weight dropping technique is believed to be mechanical, while both mechanical and vascular factors seem to operate in the clip and balloon compression techniques.
\end{abstract}

RÉSUMÉ: Nous avons comparé trois techniques de production expérimentale de lésion de la moelle chez le rat: (1) chute d'un poids, (2) compression par pince à anévrisme, (3) compression par ballon extradural. En principe, dans la technique un, la variable réside dans la force employée alors qu'une force constante de durée variable est appliquée dans les techniques deux et trois. Nous avons évalué ces différentes méthodes de lésion par la méthode du plan incliné de Rivlin et Tator en les comparant au degré de récupération. La méthode de chute d'un poids s'avéra non fiable alors que la compression par pince produisit des lésions constantes. La méthode du ballon extradural produisit une récupération complète en 3-5 minutes, mais aucune récupération après 7 minutes de compression par un ballon gonflé de $0.1 \mathrm{cc}$ d'air. A $0.2 \mathrm{cc}$ d'air aucune récupération ne fut notée après compression de 1 minute. Le facteur mécanique prédomine dans la méthode du poids échappé, alors que les facteurs mécanique prédomine dans la méthode du poids échappé, alors que les facteurs mécaniques et vasculaires sont en action dans les deux autres procédures.

Can. J. Neurol. Sci. 1983; 10:161-165

Siegel (1973) states that Galen was the first experimental neurophysiologist who sectioned spinal cords of monkeys and other animals and provided early data on differential lesions. Riese (1959) records that the notebooks of Leonarda da Vinci contained an interesting reference to the physiology of the spinal cord with a description of an unusual experiment on the frog. He noted that "the frog instantly dies when the spinal cord is pierced; and previous to this it lived without head, without heart or any bowels or intestine or skin; and here therefore it would seem lies the foundation of movement of life".

During the past 75 years, several animal models of acute spinal cord injury have been developed in an attempt to study and find an effective method to manage spinal cord injury in man. Allen (1911) described an experimental model for creating reproducible spinal cord injuries in the dog. Several investigators have subsequently employed this model, although major discrepancies in the results of experiments have been noted using minor modifications of Allen's original apparatus (Dohrmann et al, 1976; Koozekanami, 1976; Albin et al, 1967; Freeman and Wright, 1953; Kajihara et al, 1973).

Tarlov (1957) detailed the use of extradural balloon compression of the spinal cord in dogs. Subsequently this technique, with varying modifications, has been explored by others (Hansebout, et al, 1975; Tator, 1973). Eidelberg (1976) described a direct gradual cord compression technique in ferrets. Subsequently, Rivlin and Tator (1978) described a new acute cord injury model in the rat using a modified aneurysm clip.

We are reporting our experience with different experimental models of cord injury in the rat. Rats were chosen in this project because they are relatively inexpensive, readily available and have been used by previous researchers who utilize the weight dropping and aneurysm clip compression techniques. To our knowledge, the balloon compression technique has not previously been used to produce experimental spinal cord injury in rats. In the past, that might have been technically difficult. However, the recent development of very small balloons which could be easily positioned and inflated with a known quantity of gas makes this technique feasible.

\section{MATERIALS AND METHODS}

One hundred and fifty Sprague-Dawley adult female rats weighing 270-310 grams were used in this study. All animals operated upon were anesthetized with intraperitoneal pentobarbital 4 milligrams/100 gram body weight. The spinal cord injury was produced at the mid thoracic level of the spinal canal. Ten rats had no anesthetic or surgery while another group of 10 was subjected to a 5 millimeter thoracic myelectomy.

From the Department of Clinical Neurological Sciences, Division of Neurosurgery, University of Saskatchewan, Saskatoon.

Received November 23, 1982. Accepted for publication April 5, 1983.

Reprint requests to Dr. Moe Khan, Dept. of Clinical Neurological Sciences, University Hospital, Saskatoon, Saskatchewan S7N 0X0 Canada. 
These two groups served as controls to assess the two extremes of expected functional recovery. Functional ability of each animal was assessed weekly for six weeks by the incline plane method of Rivlin and Tator (1977), using a smooth surface rather than a rubber corrogated mat inclined plane. All animals were kept in a heated room $\left(28^{\circ}-30^{\circ}\right)$. One cage was alloted to each animal subjected to a surgical procedure and no more than two animals per cage in a non-operated group. Animals operated upon had their bladders expressed manually twice daily during the first week and thereafter once daily. Each surgical animal was given 0.4 milligrams gentamyacin sulphate intramuscularly daily for 14 days, beginning on day of operation. The animals operated on were bathed daily for seven days after surgery and subsequently as required.

\section{Technique 1 - Weight Dropping Injury}

Thirty rats were subjected to two-level mid-dorsal laminectomies including removal of the pedicles using a Zeiss operating microscope under sterile conditions. Injuries were produced in three groups of ten rats each using forces of 40,50 and $60 \mathrm{gram}$ centimeter respectively. This was achieved with a 5 gram impounder dropped through a vented brass tube from different heights to strike the exposed dura. The tube was maintained perpendicular to the surface using a spirit level gauge while the contact surface of the weight impacter was designed to straddle the entire width of the dorsal spinal cord and to correct for slight angulation of the spinal cord of 3 to 5 degrees. The wound was closed in anatomical layers.

A controlled group of 10 animals were subjected only to two-level mid-dorsal laminectomies with complete removal of pedicles.

\section{Technique 2 - Clip Compression Injury}

Thirty rats were subjected to similar laminectomies as described in technique 1. Compression of the spinal cord was produced by placing a modified Kerr-Lougheed aneurysm clip around the cord extradurally, using a Heifetz aneurysm clip applicator. The clip was designed and quantitated by Mr. D. Walsh (Walsh Manufacturing, Oakville, Ontario), and was a modification of that used by Rivlin and Tator (1978). The force on the spinal cord produced by this clip and spring was approximately 50 grams. After application, the clip was rapidly released from the applicator producing immediate acute cord compression. Three groups of ten rats each were injured with this clip. In the first group, the spinal cord was compressed for five seconds and then rapidly released. On the second and third groups, the clip compressed the cord of 10 and 30 seconds respectively. In ten rats the clip was opened and applied around the cord for 30 seconds and then removed. The cord was not compressed in these animals which served as controls.

\section{Technique 3 - Balloon Compression Injury}

Forty rats were used to study the extradural balloon compression method. A model 12-060-2F Fogarty arterial embolectomy balloon catheter was used to produce cord compression. The maximum air capacity of the balloon is $0.2 \mathrm{ml}$. The distal tip of the catheter is soft and short and accurate placement and location of the balloon is determined and maintained through manual fixation of the catheter. A one cc tuberculin syringe was used to inflate the balloon. Each animal was subjected to a partial mid dorsal laminectomy. The deflated balloon catheter was inserted for one centimeter above the partial laminectomy site on the dorsal surface of the spinal cord. The catheter was maintained in this position for a specified period after the balloon was inflated with air. The balloon was deflated before removal from the spinal canal. A total of 10 balloon catheters were used.

Three groups of ten rats each were subjected to 3,5 , and 7 minutes of $0.1 \mathrm{cc}$ air infalted balloon compression respectively, while one group of ten rats was subjected to $0.2 \mathrm{cc}$ balloon compression for one minute. A fifth group of 10 animals were used as controls. In these animals, the balloon catheter was inserted into the spinal extradural space for seven minutes and then removed without having been inflated.

\section{RESULTS}

Figure 1 shows the average maximum angles attained by normal rats and by rats subjected to myelectomy. The normal rats performed consistently over the six week period. At the end of the sixth week, the 10 normal rats had an average maximum response of $57^{\circ} \pm 1.10^{\circ}(\mathrm{SD})$, while the myelectomized animals maintained themselves at an average maximum angle of $19.5^{\circ} \pm 1.42^{\circ}(\mathrm{SD})$. There was no major variation in response during the six weeks of post operative assessment.

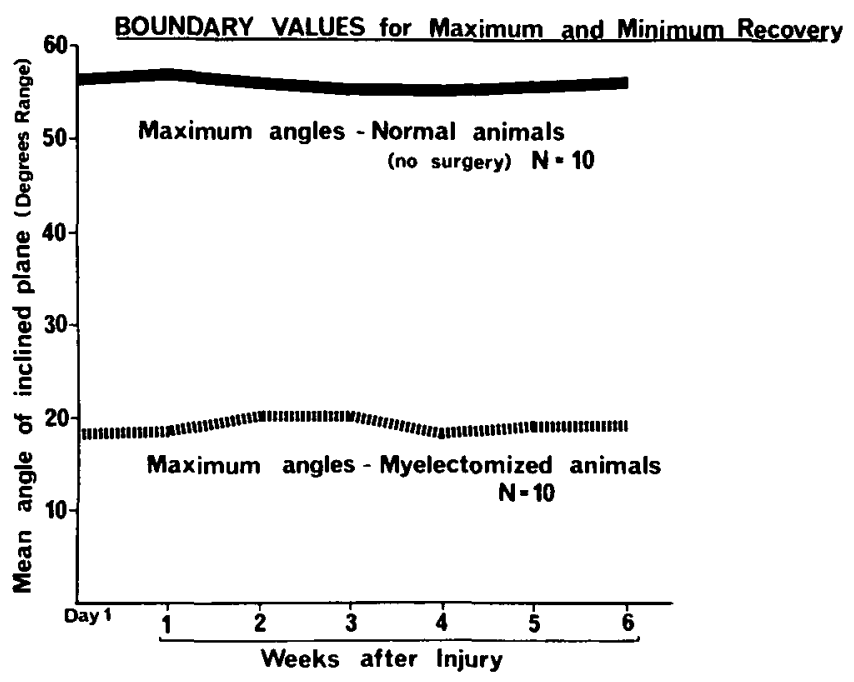

Figure I - The mean weekly maximum angles are shown for the six week assessment period. At the end of six weeks, the normal rats achieved an angle of $57^{\circ} \pm 1.10$ S.D., and the myelectomized animals had an average response of $19.5^{\circ} \pm 1.42$ S.D.

\section{Technique 1 - Weight Dropping Injury}

The 10 laminectomized rats used for controls had an average response of $55.5^{\circ} \pm 1.25$ degree (SD) at the end of the sixth post operative week. The three groups of ten rats each subjected to 40,50 , and 60 grams centimeter force injuries respectively had considerable variation in response within each group. Some animals had complete functional recovery while others had deficit comparable to the myelectomized rats. Figure 2 shows the number of rats in each group with complete, partial $\left(27^{\circ}-51^{\circ}\right)$ or no recovery at the sixth week post operative assessment. 
WEIGHT DROPPING TECHNIQUE-Recovery at 6 weeks

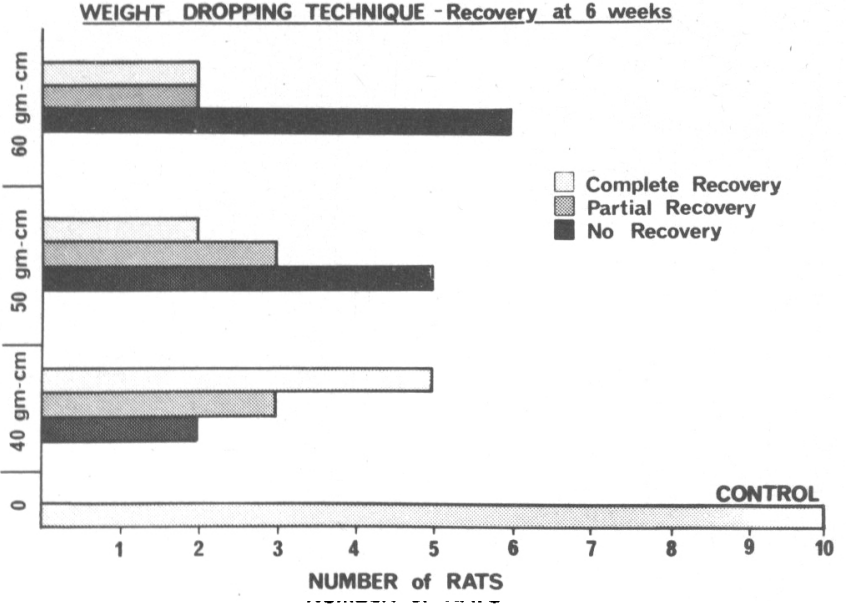

Figure $2-$ The number of rats with complete, partial $\left(27^{\circ}-51^{\circ}\right)$ or no recovery at the sixth week post operative assessment following 40 , 50 and 60 grams centimeter force injuries.

Figure 3 demonstrates graphically the results during the six week assessment period. At the end of six weeks, the group of rats subjected to 40 grams centimeter force injuries achieved a mean maximum angle of $45.5^{\circ} \pm 15.5^{\circ}(\mathrm{SD})$, the group with 50 grams centimeter force injury achieved $31.9^{\circ} \pm 15.8^{\circ}(\mathrm{SD})$ while the animals subjected to 60 grams centimeter force achieved $31.8^{\circ} \pm 15.8^{\circ}(\mathrm{SD})$. For comparison, the controlled group is included; achieving at the end of six weeks a mean maximum angle of $55.6^{\circ} \pm 1.75$ (SD). No major change in response was noted in any animal after the fourth post operative week. While there was a greater number of severe cord injuries when larger forces were used, the technique is unreliable with respect to reproducing similar clinical outcome with similar forces. Forty to eighty percent of rats performed better than the myelectomized group of animals using forces of sixty to forty grams centimeters

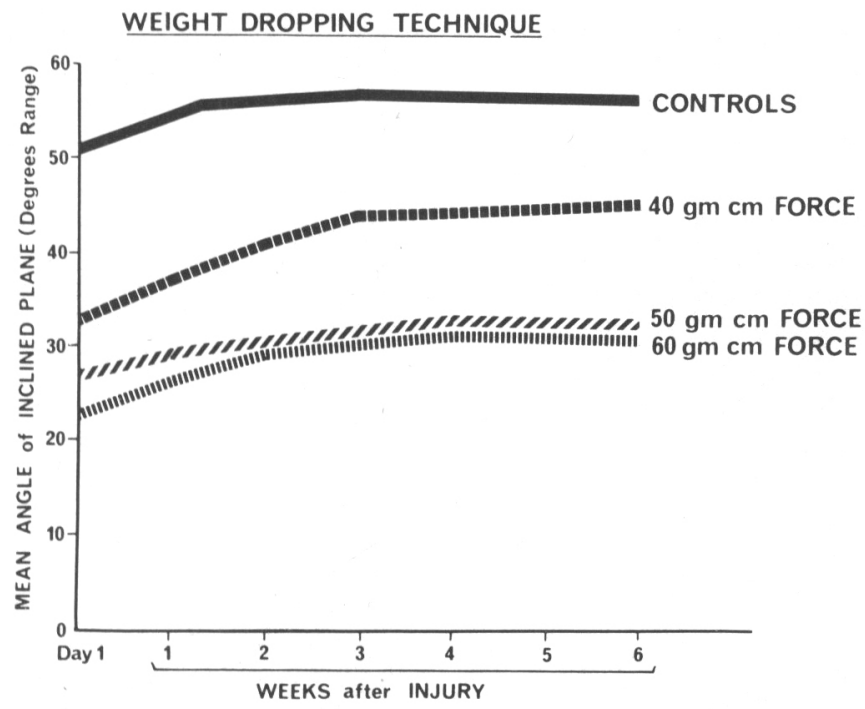

Figure 3 - The mean weekly maximum angles are shown for the six-week assessment period. At the end of six weeks, the 40,50 and 60 grams centimeter force injured groups of rats achieved an angle of $45.3^{\circ} \pm 15.5$ S.D. $31.9^{\circ} \pm 15.8$ S.D. and $31.8^{\circ} \pm 15.8$ S.D respectively. The control group had an average response of $55.6^{\circ} \pm$ 1.75 S.D. respectively. We did not use greater forces than 60 grams centimeters since preliminary studies in our laboratory using 80 grams centimeter forces in a similar group of rats resulted in immediate death in the vast majority of animals.

\section{Technique 2 - Aneurysm 2 - Aneurysm Clip Compression Injury}

Figure 4 shows the results during the six-week assessment period. At the end of six weeks, the groups of rats subjected to five second compression injury achieved a mean maximum angle of $46.3^{\circ} \pm 2.05^{\circ}(\mathrm{SD})$, the group with 10 second compression injury achieved $36.5^{\circ} \pm 1.64^{\circ}$ while the animals subjected to 30 second injury achieved only $20.8^{\circ} \pm 1.98$ degrees which is comparable to the myelectomized group. For comparison, the controlled group is included, achieving at the end of six weeks a mean maximum angle of $55.5^{\circ} \pm 1.75^{\circ}(\mathrm{SD})$.

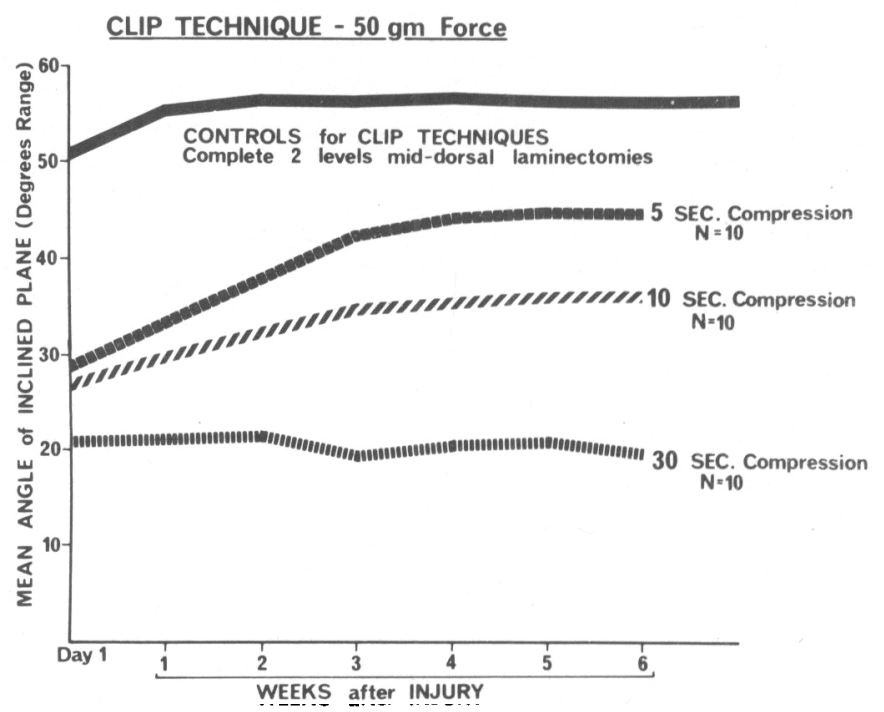

Figure 4 - The mean weekly maximum angles are shown for each group for the six week assessment period. At the end of six weeks, the 5, 10 and 30 seconds clip compression groups achieved an angle of $46.3^{\circ} \pm 2.05$ S.D., $36.5^{\circ} \pm 1.64$ S.D. and $20.8^{\circ} \pm 1.98$ S.D. respectively. The control group showed an average response of $55.5^{\circ} \pm 1.75$ S.D.

\section{Technique 3 - Extradural Balloon Compression Injury}

The balloon method of experimental cord injury in rats was technically the easiest of the three methods used. Figure 5 shows the results during the six-week assessment period for the three groups of animals injured by a $0.1 \mathrm{cc}$ balloon compression force for 3, 5, and 7 minutes respectively. At the end of six weeks, the group of rats subjected to three minutes compression injury achieved an average maximum angle of $56.2^{\circ} \pm 1.33$ degrees (SD); the animals subjected to five minutes $55.5^{\circ} \pm 1.63$ degrees (SD) and the animals subjected to seven minute compression injury achieved $19.2^{\circ} \pm 1.22$ degrees (SD).

Figure 6 shows the results during the six-week assessment period for the group of rats injured by a $0.2 \mathrm{cc}$ balloon compression force for one minute. At the end of six weeks the average maximum angle achieved by these animals was $20^{\circ} \pm 1.50$ degrees (SD), which is similar to the myelectomized group. 


\section{BALLOON COMPRESSION TECHNIQUE $-0.1 \mathrm{cC}$}

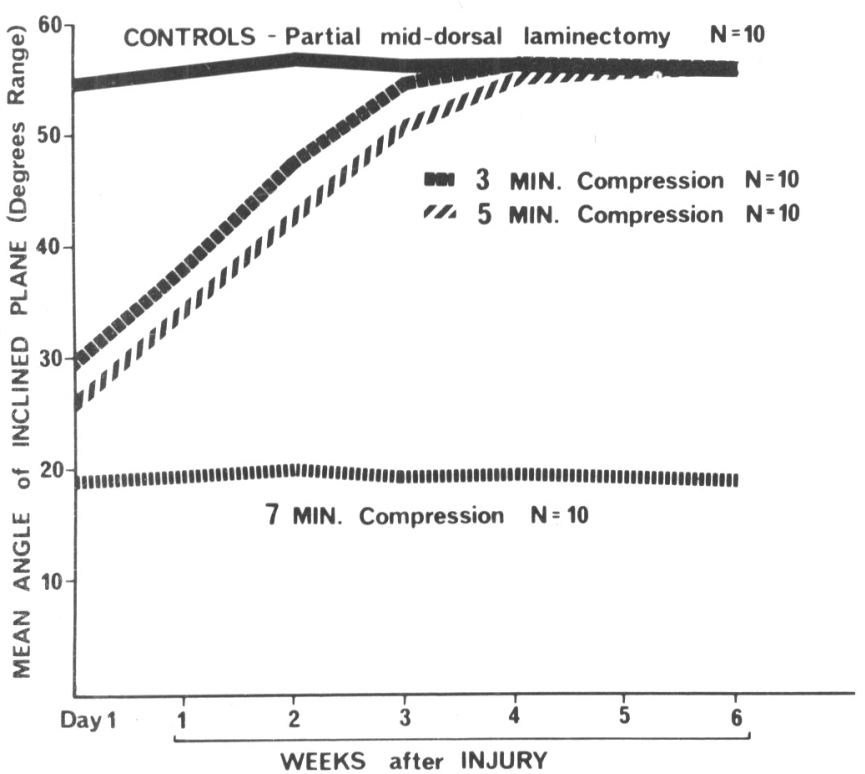

Figure 5 - The mean weekly maximum angles are shown for each group for the six week assessment period. At the end of six weeks, the 3,5 and 7 minutes $0.1 \mathrm{cc}$ balloon compression groups achieved an angle of $56.2^{\circ} \pm 1.33$ S.D., $55.5^{\circ} \pm 1.63$ S.D. and $19.2^{\circ} \pm 1.22$ S.D. respectively.

\section{Discussion}

Our main objective was to compare the relative value of three methods previously used for experimental spinal cord injuries where the clinical consequences of the injury could be measured. Since Allen (1911) first described the weight-dropping technique, many investigators have used this method or a modification of it to study experimental spinal cord injury (Freeman and Wright, 1953; Hedeman et al, 1974; Kajihara et al, 1973; Naftchi et al, 1974; Osterholm, 1974; White, et al, 1969). The major short-coming of the weight-dropping technique in our experience is related to the variability in the degree of trauma inflicted due to several concurrent factors. These probably include the size and weight differences between animals, experimental technique and apparatus, operative technique, size, weight, shape and height of the impounder, respiratory movements at impact time and quantity of subarachnoid cerebrospinal fluid below the impact site. Recent studies with the weight dropping technique suggest that several of the above factors can be eliminated or better controlled (Daniel, et al, 1975; Dohrmann, et al, 1976; Hung, et al 1975). While it may be possible to improve and standardize this technique in larger animals, our experience would suggest possible magnification of these factors when a small animal such as a rat is employed. The experience of most researchers using this technique in larger animals as well have yielded excessive variability in clinical recovery. Consequently, many other experimental models of spinal cord injuries have been pursued.

Eidelberg et al (1976) reported on a small animal model using ferrets, which involves placing various weights on the exposed spinal cord for a given period of time. A submaximal spinal cord injury was created which was reproducible clinically by a quantitative method. Subsequently, Rivlin and Tator (1977) described a new method for the clinical assessment of motor
BALLOON COMPRESSION TECHNIQUE $-0.2 \mathrm{cC}$

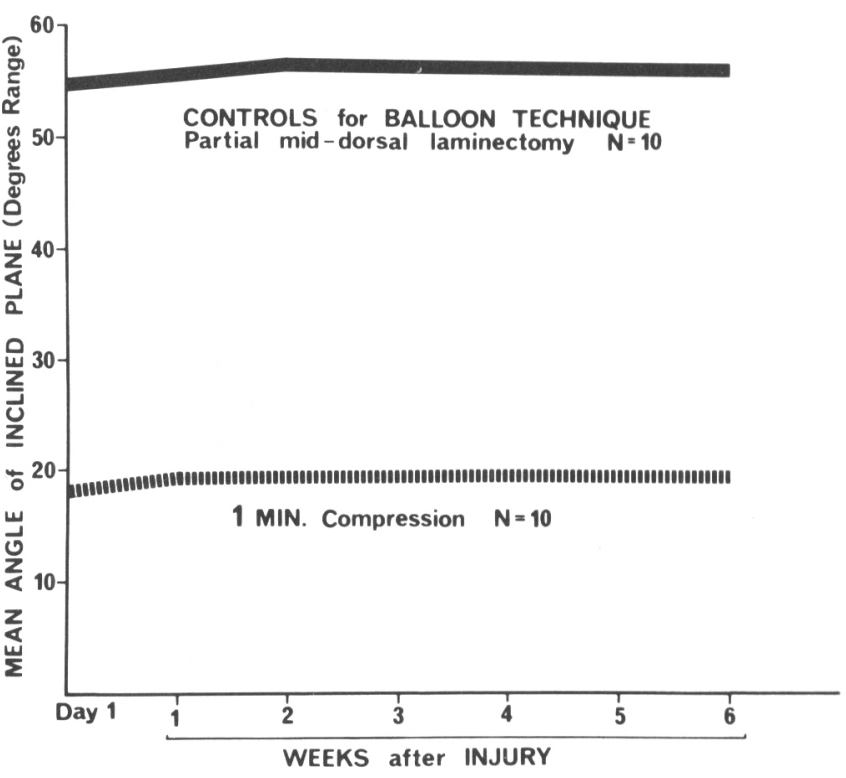

Figure 6 - The mean weekly maximum angles are shown for the group of rats injured by a $0.2 \mathrm{cc}$ balloon compression force for one minute. At the end of six weeks, this group achieved an angle of $20^{\circ} \pm 1.5$ S.D. The control group showed an average response of $56.4^{\circ} \pm 1.48$ S.D.

function in the rat and later (1978) reported on a new spinal cord injury model using a modified aneurysm clip. A standardized degree of spinal cord injury ws produced with this technique. The clip could be applied at precise locations using a consistent, quantifiable force. Our results with this technique indicate that the clinical effect of acute compression of the spinal cord is inversely related to duration of compression time, a finding already reported by Rivlin and Tator (1978). Figure 4 indicates the relationship between recovery and duration of compression. At the end of six weeks, the 5 second duration group recovered significantly better than the longer duration groups $(P<.001)$ and the 10 second compression group recovered significantly better than the 30 second compression group $(\mathrm{P}<.001)$ the latter producing clinical results equal to that obtained in the group of rats subjected to myelectomy. The major disadvantage of this method is the necessity to perform a complete laminectomy including removal of the pedicles to permit extradural passage of the anterior arm of the clip with minimal displacement of the spinal cord. We routinely performed two level mid dorsal laminectomies although this may not be necessary at the cervicothoracic junction. A considerable degree of practice is required to become proficient in this technique. We recommend using a Zeiss operating microscope, both for the laminectomy and smooth application and removal of the clips.

Tarlov (1957) introduced the extradural inflatable balloon compression technique in dogs. The duration of compression could be accurately controlled and regulated, but precise location of the balloon was difficult to maintain. Subsequently, Hansebout, et al (1975) used a balloon which could be more precisely located. This method simualtes compression of the human spinal cord by an unreduced dislocation or a fracture-dislocation of the spine. In the past, this technique required the use of large animals which are now limited for various reasons. The recent development of small inflatable balloons has made it possible to 
study larger numbers of smaller animals which are more readily available. Martin and Bloedel (1973) used a Fogarty balloon to produce spinal cord lesions in cats and their evaluation of spinal cord injury by cortical evoked potentials. The balloon used in this study could be inflated with a known quantity of gas, the duration of cord compression controlled and regulated and precise location maintained manually through the catheter.

Technically, the balloon technique is the simplest of the three techniques described. It requires minimal soft tissue dissection and bony removal. The procedure can be performed rapidly with little experience and the balloon device is simple to manipulate.

Figure 5 indicates the relationship between recovery and duration of cord compression with a $0.1 \mathrm{cc}$ air inflated balloon. At the end of six weeks, both the 3 and 5 minute compression groups recovered equally well, producing a clinical result equal to the control group with surgery. At the same time, the seven minute compression group made no recovery. Figure 6 shows the results when a $0.2 \mathrm{cc}$ inflated balloon is used to compress the cord for one minute which is also equal to that obtained in the groups subjected to myelectomy. We did not attempt to produce a submaximal spinal cord injury, but the results would indicate a steep-dose response curve which may be a disadvantage of this method. These findings would be compatible with reversible and irreversible cord ischemia, although admittedly one might have expected a faster recovery with reversible ischemia. Preliminary histological studies in our laboratory show changes in the cord of animals subjected to three and five minute compression which are compatible with ischemia, in spite of thier 'full' clinical recovery. The major cause of the cord injury would seem to be mechanical when a $0.2 \mathrm{cc}$ balloon compression force is used for one minute. With a $0.1 \mathrm{cc}$ balloon compression for three to five minutes, the short lived neurological deficit can best be explained on the basis of ischemia. The balloon technique may therefore be a suitable tool to beter differentiate between vascular and mechanical factors operative in the spinal cord injury. We believe that both mechanical and vascular factors operate to produce cord injuries using the aneurysm clip technique while the primary pathogenesis is mechanical with the weight dropping method.

The spinal cord of rats subjected to 0.1 cc balloon compression for three and five minutes showed either no histological change or degenerative neuronal changes in the gray matter at the site of compression while the spinal cords of animals subjected to the same force but for seven minutes compression showed extensive cavitation or necrosis of the cord at the site of compression.

Hence ischemia and infarction were considered to be the primary pathcgeneses of these cord injuries. The spinal cords of rats subjected to $0.2 \mathrm{cc}$ balloon compression for one minute revealed a spinal cord gap at the site of compression, not much different from the myelectomized cords of the control animals, while the cords of rats injured by the clip and weight dropping techniques showed irregular peripheral lacerations and cavitations with or without central gray matter changes. These findings were consistent with mechanical deformation of the spinal cord. Spinal cord blood flow studies in the future may help to substantiate these hypotheses.

Each of the three techniques described here has specific advantages and disadvantages. Allen's (1911) impact method for producing cord injuries would appear to reflect best the dynamics of clinical injury to the spinal cord in man. The clip and balloon compression methods, on the other hand, are probably more suitable for experimental acute spinal cord injury studies. We hope that this comparison of techniques in experimental spinal cord injury in the rat may prove of value to others in search of the answer to the pathogenesis and better management of such injuries in man.

\section{REFERENCES}

Albin, M.S., White R.J., and Locke, G.A., et al (1967). Localized spinal cord hypothermia: anesthetic effects and applications to spinal cord injury. Anesth Analg 46:8-16.

Allen, A.R. (1911). Surgery of experimental lesion of spinal cord and equivalent to crush injury of fracture dislocation of spinal column. Preliminary Report. JAMA 57:878-880.

Daniell, H.B., Wooford, W.F., Lee. W.A. and Ducker, T.B. (1975). A method of quantitating injury inflicted on acute spinal cord studies. Paraplegia 13:137-142.

Dohrmann, C.J., Panjabi, M.M., and Wagner, F.C., (1976). An apparatus for quantitating experimental spinal cord trauma. Surg Neurol 5:315-318.

Eidelberg, E.M., Staten, E., and Watkins, A.C., et al (1976). A model of spinal cord injury. Surg Neurol, 6:35-38.

Freeman, L.W., and Wright, T.W. (1953). Experimental observations of concussion and contusion of the spinal cord. Ann Surg 137:433-443.

Hansebout, R.P., Eugene, F., Kuthner F., and Romero-Sierra, C., (1975). Effects of local hypothermia and of steroids upon recovery from experimental spinal cord compression injury. Surg Neurol 4:531-536.

Hedeman, L.S., Shellenberger, M.K, and Gordon, J.H., (1974). Studies in experimental spinal cord trauma. Part 1: Alterations in catecholamine levels. J Neurosurg 40:429-434.

Hung, T.K., Albin, M.S., and Brown, T.D., et al (1975). Biomechanical responses to open experimental spinal cord injury. Surg Neurol 4:271-276.

Kajihara, K., Kawanga, H., and de la Torre, J.C., et al (1973). Demethyl sulfoxide in the treatment of experimental spinal cord injury. Surg Neurol 1:16-22.

Koozekanani, S.H., Vise, W.M., Hashemi, R.M., and McGhee, R.B., (1976). Possible mechanisms for observed pathophysiological variability in experimental spinal cord injury by the method of Allen. J Neurosurg 44:429-434.

Martin, S.H., and Bloedel, J.R., (1973). Evaluation of experimental spinal cord injury using cortical evoked potentials. J Neurosurg 39:75-81.

Naftchi, N.E., Demeny, M., and De Crescito, V., et al (1974). Biogenic amine concentrations in traumatized spinal cords of cats. Effect of drug therapy. J Neurosurg 40:52-57.

Osterholm, J.L., (1974). The pathophysiological response to spinal cord injury. The current status of related research. J Neurosurg 40:5-33.

Riese, W. (1959). A history of Neurology. M.D. Publications N.Y., pp. 223.

Rivlin, A.S., and Tator, C.H., (1978). Effect of duration of acute spinal cord compression in a new acute model in the rat. Surg Neurol 10:39-43.

Rivlin, A.S., and Tator, C.H., (1977). Objective clinical assessment of motor function after experimental spinal cord injury in the rat. $J$ Neurosurg 47:577-581.

Siegel, R.E., (1973). Galen on Psychology, Psychopathology and function and diseases of the nervous system. S. Kanger Basel, IX +310 .

Tarlov, I.M. Spinal cord compression. Springfiled, Ill., Charles C. Thomas, 1957.

Tator, C.H., (1973). Acute spinal cord injury in primates produced by an inflatable extradural cuff. Canad J Surg 16:222-231.

White, R.J., Albin, M.S., and Harris, L.S., et al (1969). Spinal cord injury: sequential morphysiology and hypothermia stabilization. Surg Forum 20:432-434. 